\title{
An Advanced Control Strategy Implementation for an Efficient Solar Inverter to Grid connected Applications
}

\author{
Krishna Chaitanya $\mathbf{M}^{\mathbf{1}}$, Sambasiva Rao G ${ }^{\mathbf{2}}$ and Amarendra Matsa ${ }^{3}$ \\ ${ }^{1}$ Research Scholar, Acharya Nagarjuna University, Guntur. Email : mllea.venkata @ gmail.com. \\ ${ }^{2}$ Professor, RVR \& JC College of Engineering, Guntur \\ ${ }^{3}$ Associate Professor, Mizoram University, Aizawl
}

\begin{abstract}
The emerging field of grid interfaced renewable energy generating opportunities to build advanced objectives to improvise and convert robust overall system. In the solar power grid integration the solar inverter plays crucial role in stability and power control. The grid has indefinite nature with different faults and generates voltage disturbances at PCC. During this stage the system must connected to grid to support and to meet the stability requirements of the grid. In this research study deliver three control objectives having reducing the transient nature of the parameters during the fault transitions with smooth control method, implementing generalized SVPWM with fixed computational time to any level grid inverter and to improve the grid inverter capabilities during grid faults with proposed control algorithm. The results are builds with the simulation platform MATLAB/Simulink.
\end{abstract}

Key words: Reactive Power control, SVPWM and Voltage Sags.

\section{INTRODUCTION}

The effective generation of green energy is emerging research filed in present research community due to the more demand in the society, green energy transform reforms and economic importance. The basic structures of green energy are abounded availability of the energy, optimized cost and environment friendly encouraging the green energy market every year 29 percent compared to conventional energies. Interconnection of large scale renewable energy to grid has great impact on power quality and system stability issues. Therefore present grid standards are being regularly improvising to maintain better system in a large scale integration of RE to grid condition. The better design of grid standards gives stable and safe operation of grid under normal and abnormal faulted conditions[1-2].

During the abnormal fault conditions the voltage disturbances i.e voltage sags is basic important power quality issue. A voltage sag is defined as reduction in voltage magnitude value from $10 \%$ to $90 \%$ for a period of one cycle to one minute. To make grid connected more robust the grid system expected to maintain following standards: 1) During the faulted condition the any system should not be disconnected from the grid. 2) To maintain voltage profile grid should be strengthen by reactive power supply. 3) Recovering active power supply after the fault closes[3-5]. Fault ride through stability is very important nature of the system to sustain reliability of the system. This restricts the condition that the supply source must maintain connectivity to increase operational stability[6].
Related to the reactive current component injection the GC curve gives the relation between amounts of reactive component injection to particular voltage sag caused by different system faults. During the past few years lot of control mechanisms are described by researchers to improvise performance of the grid connected inverter during the grid faults and controlling power for different voltage sag conditions. Different studies are concentrating to maximize current control to detect and disconnect during overcurrent conditions of fault but, these algorithms have basic drawbacks of system stability[7].

Present researchers are focusing innovative new control algorithms containing certain specific methods increase the power capability of grid connected inverters[8]. By considering all the views of present control techniques, this paper presents an advanced control strategy implementation for an efficient solar inverter to grid applications with voltage sag stability. This research article is presented with three important control objectives: 1) Reducing the transient disturbances of the parameters by considering voltage feed-forward signal. 2) Incorporating generalized SVPWM with fixed computational time for any level of multilevel inverter. 3) Implementing proposed control algorithm to maximize the inverter capability and stability by supplying appropriate power control during different faulted conditions.

This research article is organized in five sections. Section II provides detailed analysis of the proposed control algorithm. Section III Consists incorporation of generalized SVPWM with fixed computational time. Section IV gives simulation results analysis and finally section $\mathrm{V}$ consists conclusion of the research objectives.

\section{Proposed control algorithm}

The basic objective nature of the grid connected inverter is to maintain balanced grid currents during the abnormalities when both active and reactive powers are closely controlled. Due to the abnormal conditions at grid PCC voltage will unbalance and gets disturbed with voltage sags. The idealistic designed controller of the inverter should properly compensate this condition by injecting regulated currents to grid. The sequence separator is used to categorize positive and negative sequence components of the PCC voltage component. To improvise the performance at fault transitions a feed-forward PCC voltage is used to shown in Fig. 1. To eliminate excessive transients when the system operation is changed from normal condition to abnormal condition i.e. soft fault transition, a feed-forward method of signal is used. 


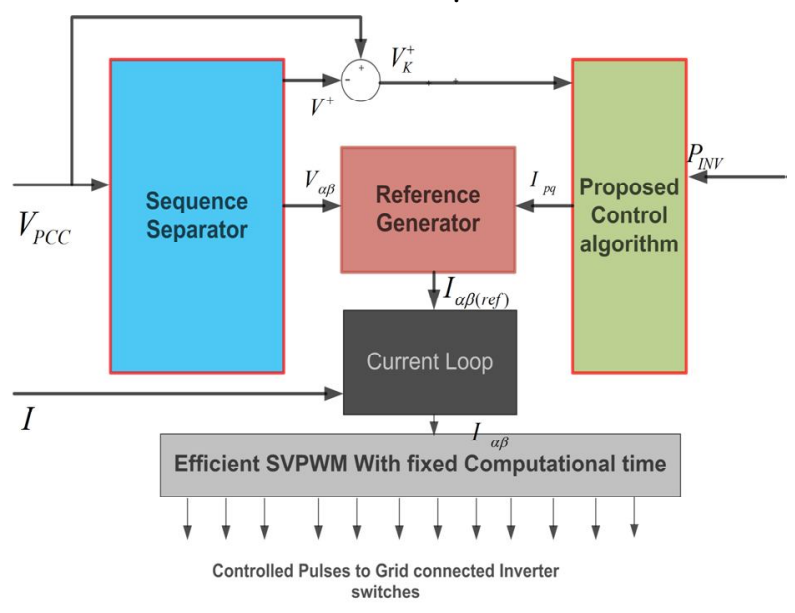

Figure 1: Proposed Cntrol Block Diagram

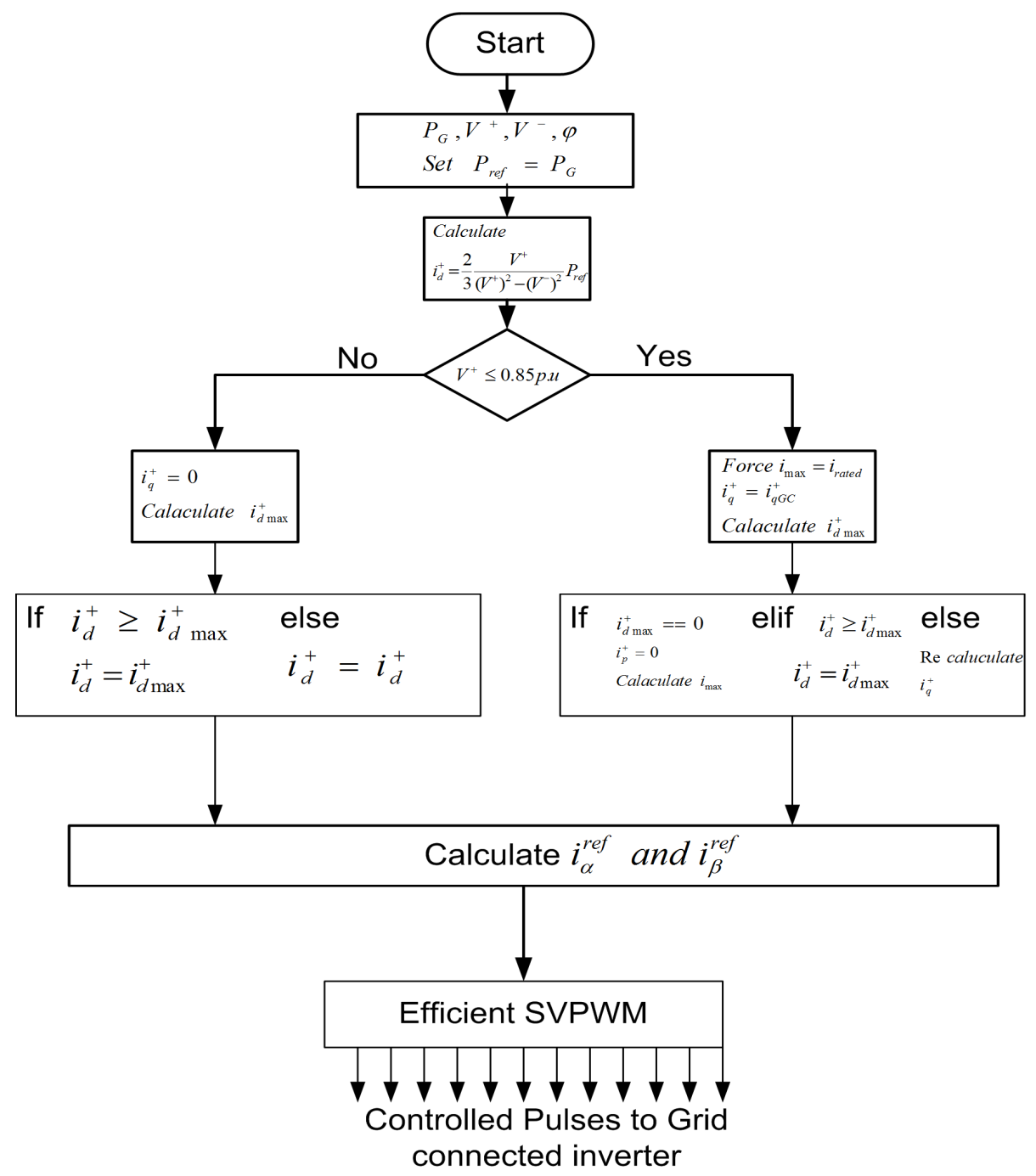

Figure 2:Flow chart of the proposed control algorithm

The faulted grid system expects reactive current feed which improves the immediate recovery of the voltage. The intensity of the reactive current component injection depends upon the voltage variation of the PCC. 


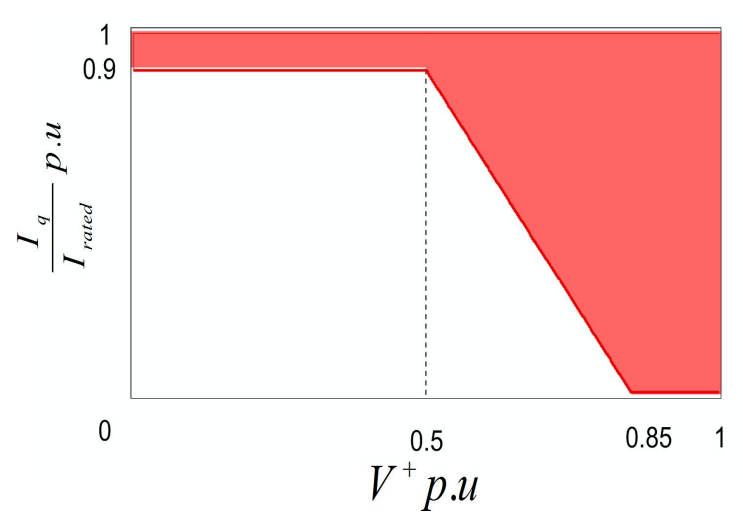

Figure 3:Standard rective current requirement curve

The characteristic nature of standard reactive component requirement curve [9] varies depending on the guidelines of each country; however, standard efforts are worked out to unify the criteria of this requirement shown in Fig.3. From the standard reference graph the controlled inverter must supply total available rated current component in the form of reactive when the grid under fault and PCC voltage dips 0.9 p.u. The magnitude of I+q supplied by the inverter to grid is determined by the standard re reactive graph.

The proposed control algorithm implements and determines the requirement of different current components of the grid connected inverter. The flow chart of the proposed control algorithm shown in Fig. 2. The generated real power at inverter PG, PCC voltage Vpcc and the phase angle are measured as input parameters to proposed control algorithm. When the grid is under normal i.e no sag condition the active current component of the inverter is to be supplied maximum to maximize the maximum active power supply. When any grid fault condition i.e voltage sag occurs $(\mathrm{V}+<0.85$ p.u) there is necessity to supply reactive current component to stabilize the PCC voltage. In the proposed control algorithm the reactive current component is designed to calculate for different conditions of the voltage sags of the PCC. The reference components of the currents are calculated based on these required active and reactive components of the currents.

These generated reference components are compared with the actual inverter currents and forms current loop which generates error signal. These error signals are the input signals to the SVPWM.

\section{EFFICIENT SVPWM WITH FIXED COMPUTATIONAL TIME}

In the proposed SVPWM the identification of the nearest three vectors (NTV) is done very quickly with $120^{\circ}$ coordinated system. Thereafter the duty ratios of NTV and switching sequence are computed as simple two-level inverter SVPWM methods. With this method of modulation the computational time is constant without depending on the level of the Multi-level inverter i.e this method is very generalized for any level of multilevel inverter. Subsequently the memory requirement for this method is low for high level multilevel inverters [10].

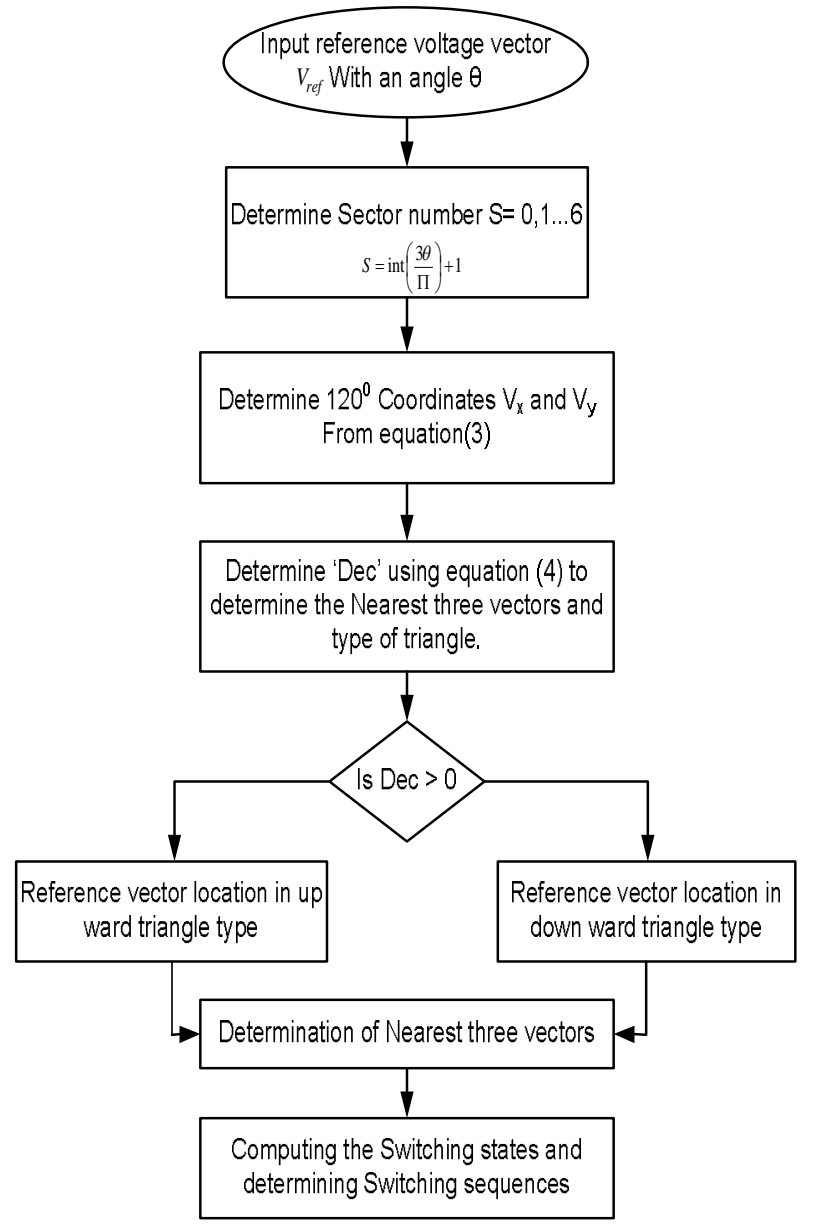

Figure 4: SVPWM with fixed computational time

The conventional method of SVPWM contains transformation from stationary axis (abc) to $\alpha \beta$ axis system. But, with this method the symmetry utilization of SVD not efficient i.e. the computation process and time increases. Whereas in the proposed method the Space Vector Diagram (SVD) of the sector 1 in 1200 coordinate is used and the vertexes coordinate points are exact integer values. This converts the computation process more convenient than $\alpha \beta$ axis system. With this new SVPWM method the identification of nearest three vector is done more quickly and easily. The duty ratio of this method is computed without look-up tables. This will generates the fixed computation time as well as optimized memory requirement to processor compared to the conventional methods. Therefore with these advantages the proposed fixed computational time SVPWM method is more cost effective and efficient to any level of multilevel inverters. 


\section{Simulation Results}

The different types of unsymmetrical faults such as LL, LL-G and L-G create voltage disturbances and unbalance at PCC. The simulation conditions are considered for two different conditions one as disturbance in one phase of voltage and two other phases are healthy. Second case is disturbance in two phases and other one phase of voltage at grid is normal.
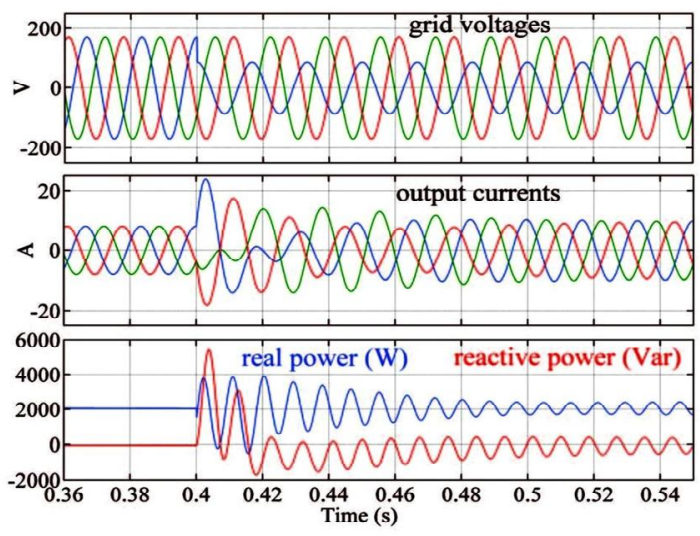

Figure 5: Voltage sag of 50\% in one phase voltage reduction (without feed-forward control).

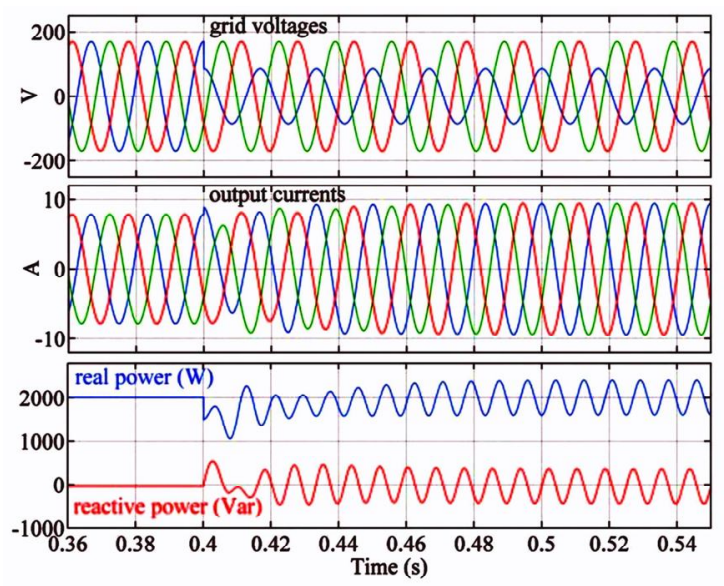

Figure 6:Voltage sag of $50 \%$ in one phase voltage reduction (with smooth transition mechanism).

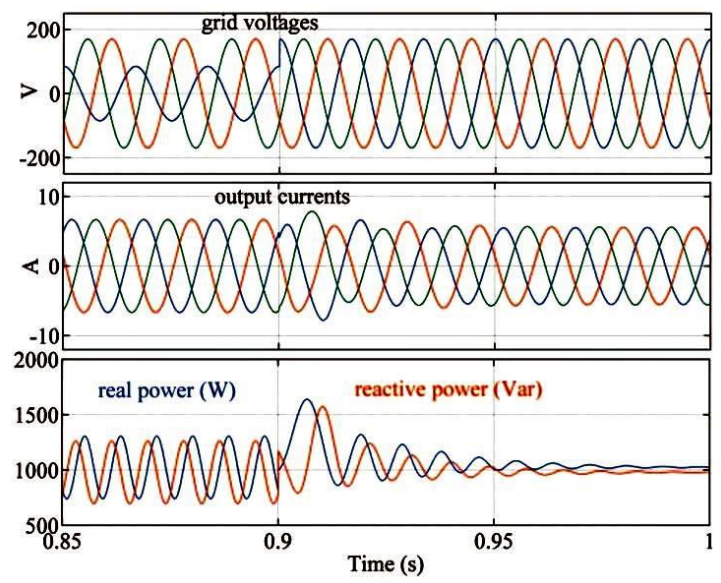

Figure 7:Transition from volage sag situlation to normal (Single phase fault)

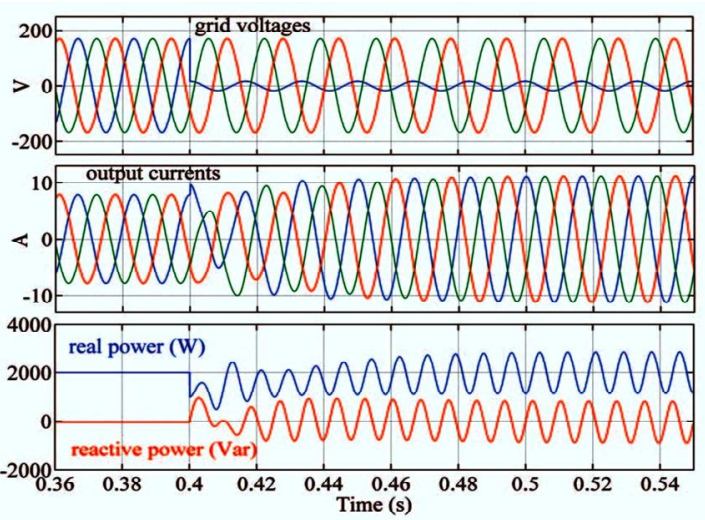

Figure 8: Voltage sag of $90 \%$ in one phase voltage reduction

A three Phase 2.5 KVA grid connected inverter is considered for MATLAB/SIMULINK simulation. Fig. 5 shows the voltage sag of $50 \%$ with one phase PCC voltage reduction without feed-forward signal control. It is clearly observed that before the transient point $\mathrm{t}=0.4 \mathrm{Sec}$. the active power is stable and reactive power supply is zero. At $t=0.4$ Sec. there is fault in one phase at PCC. This will cause high transients in currents and power supplied by inverter. It is also observed that without feed-forward control the system will takes long time to stabilize. By using feed-forward voltage signal these transients can be reduced and the inverter current and power components will be stabilized very quickly shown in Fig. 6.

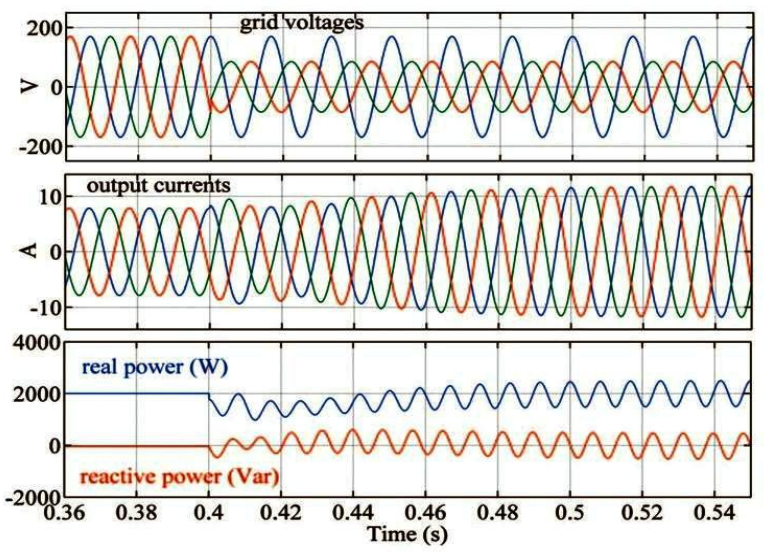

Figure 9:voltage sag of 50\% in two phase voltage reduction (with smooth transition mechanism).

Fig. 7 shows the transition of faulted voltage sag to normal condition of PCC voltage in one phase with smooth controller. With sever L-G fault in at PCC, it may cause $90 \%$ reduction of voltage sag in single phase which is shown in fig.8. It can be observed that with smooth control inverter currents are balanced very quickly with compensated magnitude increase. 


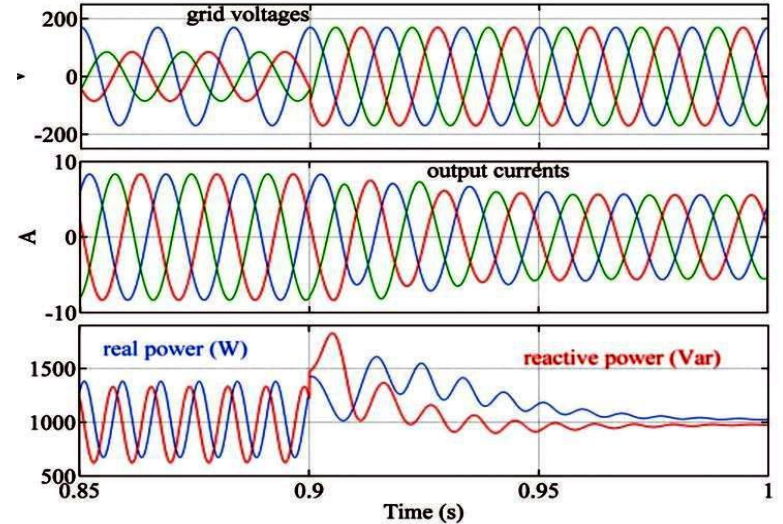

Figure 10:Transition from volage sag situlation to normal (Double line fault)

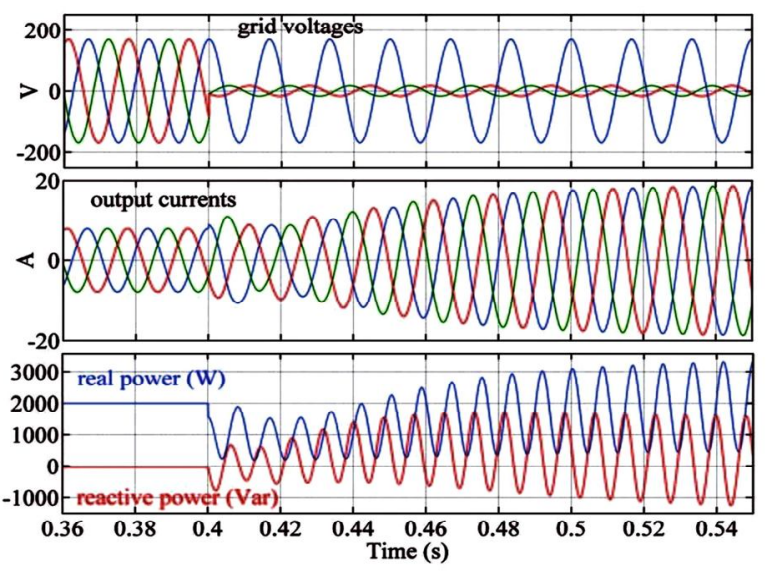

Figure 11:voltage sag of $90 \%$ in two phase voltage reduction (with smooth transition mechanism).

Fig. 9 shows the double line to ground fault with voltage sag $50 \%$ of rated voltage, which causes reduction in voltage of two phases with $50 \%$ and the remaing one phase voltage is healthy. With smooth controller operation this trasation very smooth and inverter currents are balanced. Similally Fig. 10 shows the trasation of double line to ground fult condtion to retrive normal condition. When in the case of sevear double line to ground fault the voltage sag reduction is very high. Fig. 11 shows the case of consideration of voltage sag $90 \%$ of the rated voltage and it is clearly observed from the results that thers is fast balancing in three phase inverter currents with large compensation magnitude value.

\section{CONCLUSION}

An advanced feed-forward control strategy for an grid connected inverter is presented in this research article. In one of the research objective a generalized SVPWM with fixed computational time is considered for this system. Different fault conditions are considered to test the smooth controlled grid system. Single line to ground fault with voltage sag $50 \%$ and $90 \%$ severity conditions are presented with fast dynamics in inverter currents. Double line to ground faults also considered with same severalty conditions with comprising results.

\section{REFERENCES}

[1]. S. Reichert, G. Griepentrog and B. Stickan, "Comparison between grid-feeding and grid-supporting inverters regarding power quality," 2017 IEEE 8th International Symposium on Power Electronics for Distributed Generation Systems (PEDG), Florianopolis, 2017, doi: 10.1109/PEDG.2017.7972536, pp. 1-4.

[2]. F. Mandrile, E. Carpaneto and R. Bojoi, "Grid-Tied Inverter with Simplified Virtual Synchronous Compensator for Grid Services and Grid Support," 2019 IEEE Energy Conversion Congress and Exposition (ECCE), Baltimore, MD, USA, 2019, doi: 10.1109/ECCE.2019.8912266, pp. 4317-4323,

[3]. D. Zhang and J. Fletcher, "Operation of Autonomous AC Microgrid at Constant Frequency and with Reactive Power Generation from Grid-forming, Grid-supporting and Grid-feeding Generators," TENCON 2018 - 2018 IEEE Region 10 Conference, Jeju, Korea (South), 2018, doi: 10.1109/TENCON.2018.8650193, pp. 1560-1565.

[4]. A. Kannan, M. Nuschke and D. Strau-Mincu, "LFC model for frequency stability analysis of prospective power systems with high shares of inverter based generation," 2019 IEEE Milan PowerTech, Milan, Italy, 2019, doi: 10.1109/PTC.2019.8810621, pp. 1-6.

[5]. J. Hernandez-Alvidrez and J. Johnson, "Parametric PV Grid-Support Function Characterization for Simulation Environments," 2017 IEEE 44th Photovoltaic Specialist Conference (PVSC), Washington, DC, 2017, doi: 10.1109/PVSC.2017.8366295, pp. 2153-2158.

[6]. Matsa A, Chaudhari MA, "Synchronous vector control design of multilevel inverters for AC grid applications". TENCON 2015-2015, IEEE region 10 conference, Macao, pp. 1-6.

[7]. Amarendra Matsa, Irfan Ahmed, and Madhuri A. Chaudhari, "Optimized Space Vector Pulse-width Modulation Technique for a Five-level Cascaded H Bridge Inverter, "Journal of power electronics, vol.14, no.5, Sep. 2014, pp. 937-945.

[8]. I. Ahmed; V. Borghate; Amarendra Matsa; P. Meshram; H. Suryawanshi; M. A. Chaudhari, "Simplified Space Vector Modulation Techniques for Multilevel Inverters," in IEEE Transactions on Power Electronics, Doi:10.1109/TPEL.2016.2520078.

[9]. Amarendra Matsa, MA Chaudhari, HM Suryawanshi “ Modified Synchronous Vector Control Design of Multilevel Inverters for AC Grid Applications", Electric Power Components and Systems, vol.45, no.8, Mar. 2017, pp. 881-893.

[10].Krishna chaitanya, Sambasivarao, "A Generalized SVPWM Scheme for Multilevel Inverters with Fixed Computational Time", International Journal of Innovative Technology and Exploring Engineering (IJITEE), vol.9, no.4, Feb. 2020, pp. 2823-2826. 